Full-length article

\title{
Identification of ginkgolide B metabolites in urine and rat liver cyto- chrome P450 enzymes responsible for their formation in vitro ${ }^{1}$
}

\author{
Dian-lei WANG ${ }^{2,3}$, Yan $\mathrm{LIANG}^{2}$, Wei-dong $\mathrm{CHEN}^{2}$, Lin XIE${ }^{2}$, Guang-ji WANG ${ }^{2}$, Xiao-dong $\mathrm{LIU}^{2,4}$ \\ ${ }^{2}$ Key Laboratory of Drug Metabolism and Pharmacokinetics, China Pharmaceutical University, Nanjing 210009, China; ${ }^{3}$ School of Pharmacy, Anhui \\ College of Traditional Chinese Medicine, Hefei 230038, China
}

\author{
Key words \\ ginkgolide B; metabolism; cytochrome P450 \\ enzymes; urine; liver microsomes; rat \\ ${ }^{1}$ Project supported by the Hi-Tech Research \\ and Development Program of China " 863 " (№ \\ 2003AA 2Z347A) and Jiangsu Key Laboratory \\ of Drug Metabolism and Pharmacokinetics (№ \\ BM2001201). \\ ${ }^{4}$ Correspondence to Prof Xiao-dong LIU. \\ Phn 86-25-8327-1006. \\ Fax 86-25-8530-6750. \\ E-mailxdliu@cpu.edu.cn \\ Received 2007-08-23 \\ Accepted 2007-10-29 \\ doi: $10.1111 / \mathrm{j} .1745-7254.2008 .00758 . x$
}

\begin{abstract}
Aim: To identify metabolites of ginkgolide B in rat urine, the predominant metabolism of ginkgolide B and the major cytochrome (CYP) P450 enzymes responsible for the metabolism of ginkgolide B in rat liver microsomes. Methods: A liquid chromatography quadrupole mass spectrometer and liquid chromatography ion-trap-time-of-flight mass spectrometer with electrospray ionization in negative-ion mode were used for the structure elucidation of metabolites in rat urine and liver microsome incubation. Various selective CYP450 inhibitors were applied to investigate their effects on the metabolism of ginkgolide $\mathrm{B}$ and the formation of the major metabolite in rat liver microsomes. Results: Three metabolites were identified in rat urine. One hydroxyl metabolite of ginkgolide $\mathrm{B}$ were identified in rat liver microsomes, and quinidine uncompetitively inhibited the formation of the metabolite; its inhibitor constant $\left(K_{\mathrm{i}}\right)$ value for the inhibition of hydroxyl metabolite was estimated to be $8 \mu \mathrm{mol} / \mathrm{L}$, while $\alpha$-naphthoflavone, ketoconazole, sulfaphenazole, and diethyldithiocarbamate had no inhibitory effects. Conclusion: Ginkgolide B was metabolized to its hydroxyl metabolite in rats, and CYP2D6 was the major rat CYP isoform responsible for the ginkgolide B metabolism in rat liver microsomes.
\end{abstract}

\section{Introduction}

As an important active constituent of Ginkgo biloba extract, ginkgolide B is a highly selective and competitive platelet-activating factor (PAF) receptor antagonist ${ }^{[1]}$. In recent clinical and experimental experiments, ginkgolide $\mathrm{B}$ has been reported to be effective against ischemic brain injury ${ }^{[2,3]}$, platelet aggregation and thrombosis ${ }^{[4]}$, and inflammatory $^{[5]}$ and central nervous system diseases, such as postischemic neuronal damage, dementia, and Alzheimer's disease $^{[6,7]}$.

Now, ginkgolide B is being developed for treating cerebrovascular accidents. The preclinical pharmacokinetics of ginkgolide B have been reported in our laboratory; the data showed that $45 \%$ and $2.6 \%$ of ginkgolide $\mathrm{B}$ administered to rats were excreted into urine and feces in $48 \mathrm{~h}^{[8]}$, respectively, suggesting that nearly $50 \%$ of ginkgolide B may undergo metabolism in vivo. Up to now, the detailed meta- bolic pathway of ginkgolide B in rat has not been reported.

The purpose of this experiment was to identify the metabolites of ginkgolide B in rat urine, the predominant metabolism of ginkgolide $\mathrm{B}$ in rat liver microsomes in vitro, and to identify the major cytochrome (CYP) P450 enzymes responsible for its metabolism.

\section{Materials and methods}

Chemicals Ginkgolide B and limonin (as the internal standard [IS]) were obtained from the National Institute for the Control of Pharmaceutical and Biological Products (Beijing, China). Glucose-6-phosphate dehydrogenase (G-6-PDH; type V), $\alpha$-nicotinamide adenine dinucleotide phosphate (NADP), glucose-6-phosphate (G-6-P), $\alpha$-naphthoflavone ( $\alpha$-Naph), sulfaphenazole (Sul), quinidine (Qui), and diethyldithiocarbamate (DDC) were purchased from Sigma (St Louis, MO, USA). Ketoconazole 
(Ket) was kindly provided by Nanjing Second Pharmaceutical Factory (Nanjing, China). Ginkgolide B emulsion was presented by Beijing 303 Hospital (Beijing, China). HPLC-grade methanol was purchased from Fisher Scientific (Fair Lawn, NJ, USA). All other supplies were available from standard commercial sources.

Animal Ten Sprague-Dawley rats (5 male and 5 female, $200 \pm 20 \mathrm{~g}, 7$ weeks of age) were obtained from the Experimental Animal Center of China Pharmaceutical University (Nanjing, China), and the animal experiments were approved by the Animal Ethics Committee of China Pharmaceutical University.

Rat urine specimen collection and sample preparation Six Sprague-Dawley rats (3 male and 3 female) were fasted for $10 \mathrm{~h}$ and then a single dose of ginkgolide B emulsion $(4 \mathrm{mg} / \mathrm{kg})$ was injected via the caudal vein. The rats were placed in the metabolism cages and the urine was collected at $0-8 \mathrm{~h}$ and immediately frozen and stored at -20 ${ }^{\circ} \mathrm{C}$ until analysis.

In total, $1 \mathrm{~mL}$ methanol was added to $20 \mu \mathrm{L}$ rat urine in a $2 \mathrm{~mL}$ centrifuged tube. The tubes were mixed for $5 \mathrm{~min}$ and centrifuged for $5 \mathrm{~min}$ at $10000 \times g ; 2 \mu \mathrm{L}$ supernatant was injected into the liquid chromatography (LC) mass spectrometer (MS) system.

Microsomal incubations and sample preparation The rat liver microsomes were prepared by differential centrifugation $^{[9]}$, and the microsomal protein concentration was determined by the method of Lowry et $a l^{[10]}$.

Substrate concentrations of $1-100 \mu \mathrm{mol} / \mathrm{L}$, microsomal protein of $0.5-2 \mathrm{~g} / \mathrm{L}$, and incubation times of 5-90 $\mathrm{min}$ were used to optimize assay conditions. A typical incubation mixture consisted of $100 \mathrm{mmol} / \mathrm{L}$ potassium phosphate buffer ( $\mathrm{pH}$ 7.4), an NADPH-generating system $(5 \mathrm{mmol} / \mathrm{L}$ $\mathrm{MgCl}_{2}, 10 \mathrm{mmol} / \mathrm{L}$ G-6-P, $1 \mathrm{mmol} / \mathrm{L}$ NADP, $1 \mathrm{kU} / \mathrm{L}$ G-6$\mathrm{PDH}$ ), and $1 \mathrm{~g} / \mathrm{L}$ microsomal protein in a final volume of $1 \mathrm{~mL}^{[9]}$. Before the addition of the substrate, the incubation mixtures were prewarmed for $5 \mathrm{~min}$ at $37{ }^{\circ} \mathrm{C}$. Reactions was initiated by the addition of the substrate, and the concentration of the substrate for all incubations was 20 $\mu \mathrm{mol} / \mathrm{L}$. The incubations were conducted at $37{ }^{\circ} \mathrm{C}$ for 0.5 $\mathrm{h}$, and the reaction was terminated by adding $10 \mu \mathrm{L}$ of $10 \%$ $\mathrm{HClO}_{4}$. The samples were centrifuged $(20000 \times g)$ at $4{ }^{\circ}$ $\mathrm{C}$ for $10 \mathrm{~min}$, and the supernatant was separated from the precipitated protein and concentrated by evaporation under a gentle stream of nitrogen. The residues were then reconstituted in $200 \mu \mathrm{L}$ methanol followed by centrifugation at $20000 \times \mathrm{g}$ for $10 \mathrm{~min}$; an aliquot of $10 \mu \mathrm{L}$ was injected into the LC-MS system. Incubations without NADPH served as negative controls.
Identification of metabolites using LC-MS and LC ion-trap-time-of-flight MS in rat urine and microsomal incubations Urine and incubations samples were analyzed by LC quadrupole MS (LC/ESI-MS; Quadrupole MS, Shimadzu, Kyoto, Japan) and LC ion-trap-time-offlight MS (LC-IT-TOFMS; Shimadzu, Japan). LC/ESI-MS was performed for the profile of metabolites of ginkgolide $\mathrm{B}$, and mass spectrometric conditions were optimized to obtain maximum sensitivity; the curved desolvation line voltage was fixed as that in Tuning, the probe high voltage was set at $4.5 \mathrm{kV}$, Q-array voltage of DC $-35 \mathrm{~V}$, and RF $150 \mathrm{~V}$. Mass spectra were obtained at a dwell time of $1 \mathrm{~s}$ in scan mode. The accuracy masses, formulas, and the possible structure of the metabolite were obtained by using an LC-IT-TOF-MS equipped with an electrospray ionization source (negative-ionization mode). The probe voltage was $4.5 \mathrm{kV}$, and both the curved desolvation line temperature and the block heater temperature were $200{ }^{\circ} \mathrm{C}$. The ion accumulation time and isolation time were set at 30 and 20 $\mathrm{ms}$, respectively. Argon was used as collision gas and its inflow rate to the ion trap was set $50 \%$ during collision induced dissociation (CID). The CID energy and times were $50 \%$ and $30 \mathrm{~ms}$, respectively.

Full-scan quadrupole MS spectra were first acquired for molecular ions of parent compounds and relevant metabolites. Subsequently, the ion trap mass analyzer could be used for the $\mathrm{MS}^{\mathrm{n}}$ analysis and could give the maximum amount of structural information by CID of appropriate molecular ions that were selected; the accuracy masses, formulas of the molecular ions, and their fragments were obtained by using the TOF analyzer.

The separation of metabolites was achieved on ODS and HPLC columns (Shim-pack, $5 \mu \mathrm{m}, 2.0 \mathrm{~mm}$ ID $\times 150$ mm; Shimadzu, Japan) using a LC2010 series chromatography system (Shimadzu, Japan) consisting of 2 pumps, an autosampler, and a column oven. A gradient elution mode was adopted using 2 mobile phases: $0.04 \%$ of triethylamine water $(v / v)$ and methanol. The flow rate was $0.2 \mathrm{~mL} / \mathrm{min}$. The column was equilibrated with $25 \%$ ginkgolide $\mathrm{B}$ at 0 min. After an injection of the sample, the methanol content was linearly increased to $85 \%$ at $8 \mathrm{~min}$. Then the percentage of ginkgolide $\mathrm{B}$ was linearly decreased within 2 min to $25 \%$ of the initial composition, and held to equilibrate the column for $2 \mathrm{~min}$ before the application of the next samples. Data acquisition and processing were accomplished using Shimadzu LCMS solution version 3.40 for the LCIT-TOF-MS system.

Characterization of $\mathbf{P 4 5 0}$ isoforms involved in the 
formation of ginkgolide $B$ metabolites in rat liver microsomes The inhibition of the ginkgolide B metabolism was evaluated using various selective chemical inhibitors that contained $\alpha$-Naph for CYP1A2, Qui for CYP2D6, DDC for CYP2E, Sul for CYP2C9, and Ket for CYP3A. The final concentration of ginkgolide B was $20 \mu \mathrm{mol} / \mathrm{L}$, and the concentration range of inhibitors was $2.5-20 \mu \mathrm{mol} /$ $\mathrm{L}$ for Qui, $12.5-100 \mu \mathrm{mol} / \mathrm{L}$ for $\alpha-\mathrm{Naph}$ and Sul, $6.25-50$ $\mu \mathrm{mol} / \mathrm{L}$ for $\mathrm{DDC}$, and $0.5-5 \mu \mathrm{mol} / \mathrm{L}$ for Ket in microsomal incubations ${ }^{[11]}$. Rat liver microsomes $(1 \mathrm{~g} / \mathrm{L})$ were preincubated with various concentrations of inhibitors for 5 min at $37^{\circ} \mathrm{C}$, followed by the addition of buffer. The incubation mixtures were prewarmed for $5 \mathrm{~min}$ in the NADPHregenerating system before the reactions were initiated by the addition of the substrate; then the incubations were conducted for $0.5 \mathrm{~h}$ and terminated as described earlier. As the inhibitors were dissolved in methanol, pure methanol was included in the control incubations (without inhibitors) to rule out any effects of the solvent on the microsomal activity. The final concentration of the organic solvent in the incubation system was $1 \%$.

After identifying the major metabolic enzyme involved in the metabolism of ginkgolide B in vitro, the microsomes were incubated with various concentrations of ginkgolide $\mathrm{B}(0.5-20 \mu \mathrm{mol} / \mathrm{L})$ in the absence and presence of the various concentrations of the inhibitors; all of the incubations were carried out as described before. Then the Lineweaver-Burk plot of ginkgolide B oxide activity in the absence or presence of the inhibitors was compared with the enzyme kinetics characteristics of the inhibition types $\left(V_{\max }\right.$ and $\left.K_{\mathrm{m}}\right)$. The Lineweaver-Burk plot and linear regressions were applied for the inhibition study and for the calculation of $K_{\mathrm{i}}$ values.

The $0.2 \mathrm{~mL}$ incubation mixtures were added to $10 \mu \mathrm{L}$ of $1 \mathrm{mg} / \mathrm{L}$ IS (limonin) solution, extracted with $1.2 \mathrm{~mL}$ acetoacetate and centrifuged at $3000 \times \mathrm{g}$ for $10 \mathrm{~min}$. Then the organic layer was removed and evaporated under a stream of nitrogen at $45{ }^{\circ} \mathrm{C}$. The residue was re-dissolved in 200 $\mu \mathrm{L}$ of mobile phase, and an aliquot $(5 \mu \mathrm{L})$ was injected into the LCMS system. The metabolites in the incubation mixture were determined using a LC2010 series chromatography system coupled to a quadrupole mass spectrometer (Shimadzu, Kyoto, Japan). MS spectrometer was operated in negative ion electrospray mode and analyte detection was performed in the selected ion monitoring mode. The LC separation condition was identical with the described above. Data acquisition and processing were accomplished using Shimadzu LCMS solution version 2.02 worked on Windows 2000. As $M_{1}$ standards were not available, the relative quantification of the metabolite concentrations in the incubation were compared using metabolite peak area ratios to the IS obtained for the respective samples.

\section{Results}

In vivo identification of metabolites of ginkgolide B in rat urine The full-scan mass spectrum was obtained from urine sample after ginkgolide B was intravenously administered to the rats and compared with the blank urine samples (Figure 1) to discover the main possible metabolites in rat urine. The $[\mathrm{M}-\mathrm{H}]^{-}$ions of the possible metabolites were at $m / z 439\left(\mathrm{M}_{1}\right), m / z 441\left(\mathrm{M}_{2}\right)$, and $m / z 457\left(\mathrm{M}_{3}\right)$, respectively. Thus, the molecular weights of $\mathrm{M}_{1}, \mathrm{M}_{2}$, and $\mathrm{M}_{3}$ were 440 , 442, and 458 , respectively. No significant differences were detected in the formation of the metabolites between the male and female rats. The accuracy mass data, formulas, and the possible structure of the metabolites were obtained by using a LC-IT-TOF-MS (Table 1). The [M-H] ions of $\mathrm{M}_{1}, \mathrm{M}_{2}$, and $\mathrm{M}_{3}$ were increased by 16,18 , and $34 \mathrm{Da}$, respectively, compared to that of ginkgolide $\mathrm{B}$. The measured accuracy masses of the $m / z 439$ metabolite of ginkgolide $\mathrm{B}$ indicated the charge of $+\mathrm{O}$ moiety from the parent compound, which is consistent with its being the corresponding hydroxyl metabolite. The measured accuracy masses of the $\mathrm{m} / \mathrm{z} 441$ metabolite of ginkgolide B indicated the charge of $+\mathrm{H}_{2} \mathrm{O}$ moiety from the parent compound. Relative to ginkgolide $\mathrm{B}$, biotransformation to $\mathrm{m} / \mathrm{z}$ 457 resulted in a charge of $+\mathrm{H}_{2} \mathrm{O}_{2}$. As ginkgolide $\mathrm{B}$ readily dissolved in the basic solution, recovered quantitatively on subsequent acidification ${ }^{[12]}$, and was present in 2 forms in vivo by using ${ }^{3} \mathrm{H}$-ginkgolide $\mathrm{B}$ : the original ginkgolide $\mathrm{B}$ with its ring closed and the second form with one of the rings open ${ }^{[13]}$, we can tentatively presume that $M_{2}$ was a hydrolysis metabolite of ginkgolide $\mathrm{B}$, and $\mathrm{M}_{3}$ was a hydrolysis product of $\mathrm{M}_{1}$.

The most abundant product ion of $\mathrm{m} / \mathrm{z} 367.1422$ was formed by the loss of $2 \mathrm{CO}$ from the molecular ion at $\mathrm{m} / \mathrm{z}$ 423.1334. The main fragment ions of $m / z 439.1253$ and 457.1385 in the $\mathrm{MS}^{2}$ spectra were $m / z 383.13$ by the loss of $2 \mathrm{CO}$ (Figure 2). This suggests that ginkgolide $\mathrm{B}$ and $\mathrm{M}_{1}, \mathrm{M}_{2}$, and $\mathrm{M}_{3}$ have a similar mass schizolysis rule and structure core. According to the above analysis, we can tentatively presume the proposed metabolic pathway of ginkgolide B in rats (Figure 3).

In vitro identification metabolism of ginkgolide $B$ in rat microsomes incubations Following the incubation of ginkgolide $\mathrm{B}$ with rat liver microsomes, ginkgolide $\mathrm{B}$ was rapidly metabolized, and only 1 metabolite $\left(\mathrm{M}_{1}\right)$ was 

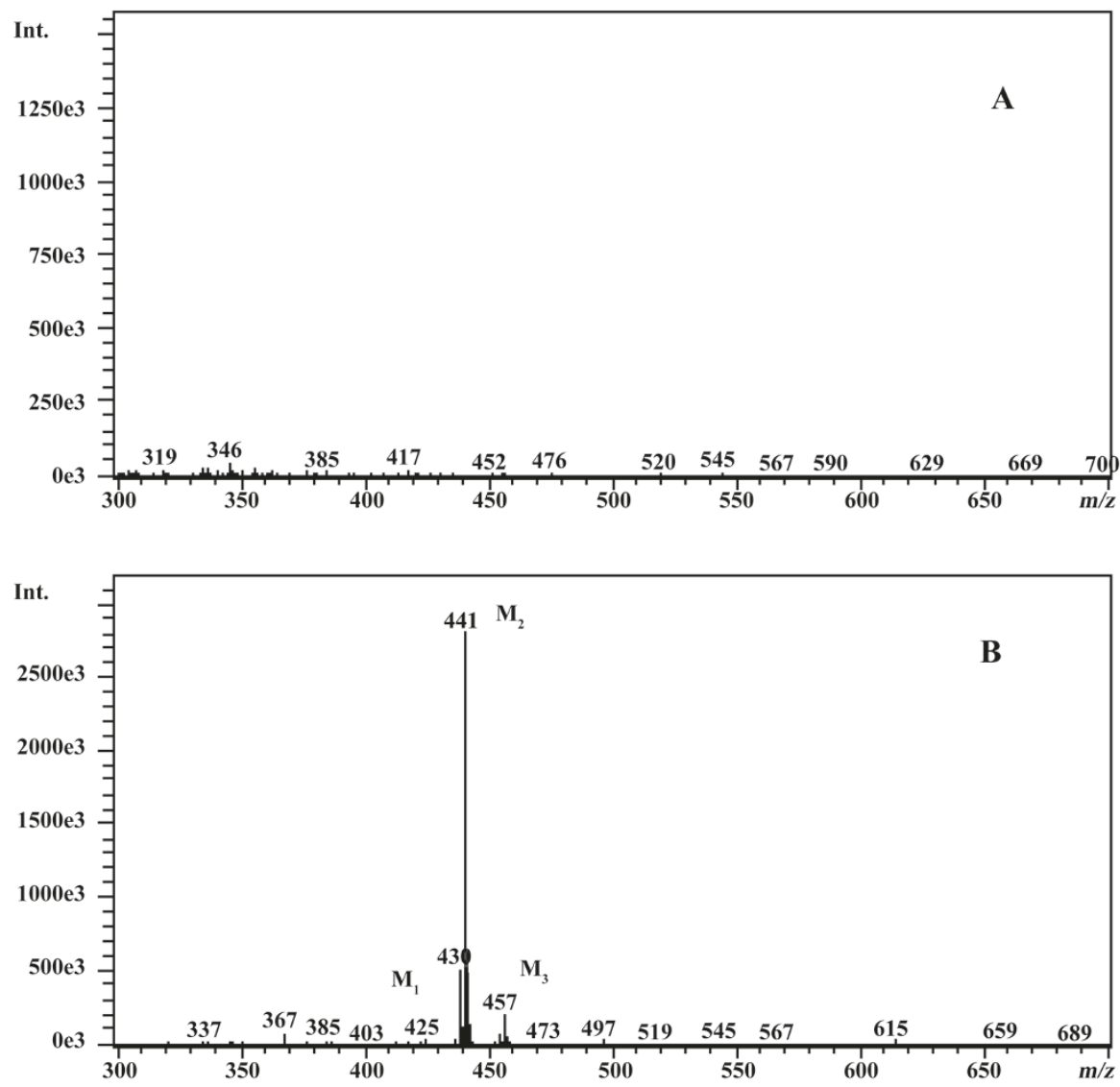

Figure 1. Full scan (-) MS spectra of blank rat urine (A) and rat urine after intravenous administration of ginkgolide B. (B) $\mathbf{M}_{1}(m / z 439), \mathbf{M}_{2}(m / z 441)$, and $\mathrm{M}_{3}(\mathrm{~m} / \mathrm{z} 457)$, respectively.

Table 1. Measured accuracy masses of the $[\mathrm{M}-\mathrm{H}]^{-}$ions of ginkgolide $\mathrm{B}$ and its metabolites formed in rat urine.

\begin{tabular}{|c|c|c|c|c|c|}
\hline Compound & $\begin{array}{l}\text { Measured mass of } \\
{[\mathrm{M}-\mathrm{H}]^{-} \text {ions/Da }}\end{array}$ & $\begin{array}{l}\text { Predicted mass of } \\
{[\mathrm{M}-\mathrm{H}]^{-} \text {ions/Da }}\end{array}$ & $\begin{array}{l}\text { Suggested elemental } \\
\text { composition }\end{array}$ & $\begin{array}{r}\text { Deviatio } \\
\mathrm{mDa}\end{array}$ & $\begin{array}{l}\text { Calculated mass } \\
\text { ppm }\end{array}$ \\
\hline Parent & 423.1334 & 423.1291 & $\mathrm{C}_{20} \mathrm{H}_{24} \mathrm{O}_{10}$ & -4.3 & -10.16 \\
\hline Metabolite $\mathrm{M}_{1}$ & 439.1253 & 439.1240 & $\mathrm{C}_{20} \mathrm{H}_{24} \mathrm{O}_{11}$ & -1.3 & -2.96 \\
\hline Metabolite $\mathrm{M}_{2}$ & 441.1434 & 441.1397 & $\mathrm{C}_{20} \mathrm{H}_{26} \mathrm{O}_{11}$ & -3.7 & -8.39 \\
\hline Metabolite $\mathrm{M}_{3}$ & 457.1385 & 457.1346 & $\mathrm{C}_{20} \mathrm{H}_{26} \mathrm{O}_{12}$ & -3.9 & -8.53 \\
\hline
\end{tabular}

isolated in the incubation (Figure 4). Their MS spectra were obtained using an electrospray ionization interface under negative-ion mode (Figure 5). Their accuracy mass data and formulas were obtained by using a LC-IT-TOFMS (Table 2). The accuracy masses suggested elemental composition of the main fragment $\mathrm{MS}^{2}$ ions of ginkgolide $\mathrm{B}$, and its metabolite were compared in rat liver microsomes obtained by the CID of the corresponding $[\mathrm{M}-\mathrm{H}]^{-}$ions (Table $3)$.
Compared to ginkgolide $\mathrm{B}\left(\mathrm{C}_{20} \mathrm{H}_{24} \mathrm{O}_{10}, \mathrm{~m} / z\right.$ 423.1326), biotransformation to $\mathrm{M}_{1}\left(\mathrm{C}_{20} \mathrm{H}_{24} \mathrm{O}_{11}, m / z\right.$ 439.1258) resulted in charge of $+\mathrm{O}$ moiety. Furthermore, the main fragment $\mathrm{MS}^{2}$ ions of ginkgolide B $(\mathrm{m} / \mathrm{z} 367.1423)$ and $\mathrm{M}_{1}(\mathrm{~m} / \mathrm{z}$ 383.1369), respectively, by using and ion trap mass analyzer, indicated the loss of the 2CO group of ginkgolide $\mathrm{B}$ and its metabolites, which demonstrated ginkgolide $\mathrm{B}$ and $\mathrm{M}_{1}$ have a similar mass schizolysis rule and structure core. According to above analysis, we could tentatively presume 

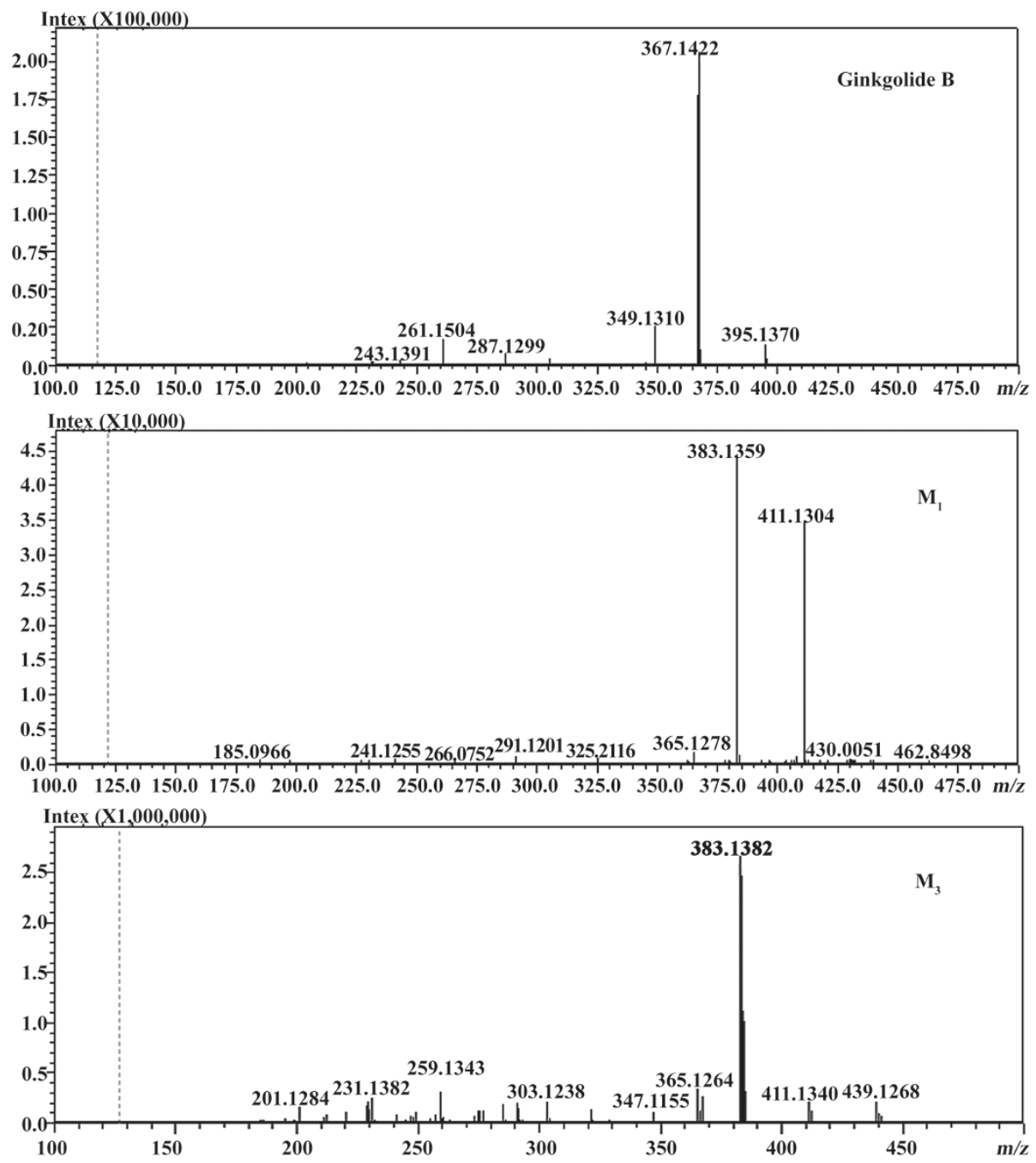

Figure 2. Main fragment $\mathrm{MS}^{2}$ ions of ginkgolide $\mathrm{B}$ and its metabolites.

that $\mathrm{M}_{1}$ was a hydroxyl metabolite of ginkgolide $\mathrm{B}$ (Figure $6)$.

Inhibition study with chemical inhibitors When the rat liver microsomes were incubated using various concentrations of the microsomal protein for various time periods, $1 \mathrm{~g} / \mathrm{L}$ microsomal protein and the $30 \mathrm{~min}$ time frame were found to be optimal incubation conditions. The effect of various substrate concentrations of 1-100 $\mu \mathrm{mol} / \mathrm{L}$ on the rate of the metabolite formation demonstrated that the $K_{\mathrm{m}}$ for $\mathrm{M}_{1}$ was approximately $4 \mu \mathrm{mol} / \mathrm{L}$. A substrate concentration of $20 \mu \mathrm{mol} / \mathrm{L}$ was chosen for further experiments, considering the concentration levels in liver tissues (approximately $20 \mu \mathrm{mol} / \mathrm{g}$ liver tissue) in vivo ${ }^{[8]}$, and the linearity and the sensitivity of the detection of $\mathrm{M}_{1}$ and the $K_{\mathrm{m}}$ value of the $M_{1}$ metabolite.

The effects of the inhibitors on the formation of $M_{1}$ are presented in Figure 7. Qui, the specific inhibitor of CYP2D6, could inhibit the formation of $\mathrm{M}_{1}$, while other inhibitors had no significant inhibitory effects on the $M_{1}$ formation. After identifying CYP2D6 involved in the metabolism of ginkgolide $\mathrm{B}$ in vitro, the microsomes were incubated with various concentrations of ginkgolide $B$ $(0.5-20 \mu \mathrm{mol} / \mathrm{L})$ in the absence and presence of Qui $(0-20$ $\mu \mathrm{mol} / \mathrm{L})$. The Lineweaver-Burk plot of ginkgolide B oxide activity in the rat liver microsomes in the absence or presence of Qui is presented in Figure 8. The LineweaverBurk plot of ginkgolide B oxide activity in the rat liver microsomes in the absence or presence of Qui was parallel, which consistent with the enzyme kinetics characteristics of the uncompetitive inhibition types (decreased in $V_{\max }$ and $\left.K_{\mathrm{m}}\right)$. The value of $K_{\mathrm{i}}$ was estimated to be $8 \mu \mathrm{mol} / \mathrm{L}$ using the Lineweaver-Burk plot and linear regressions. 


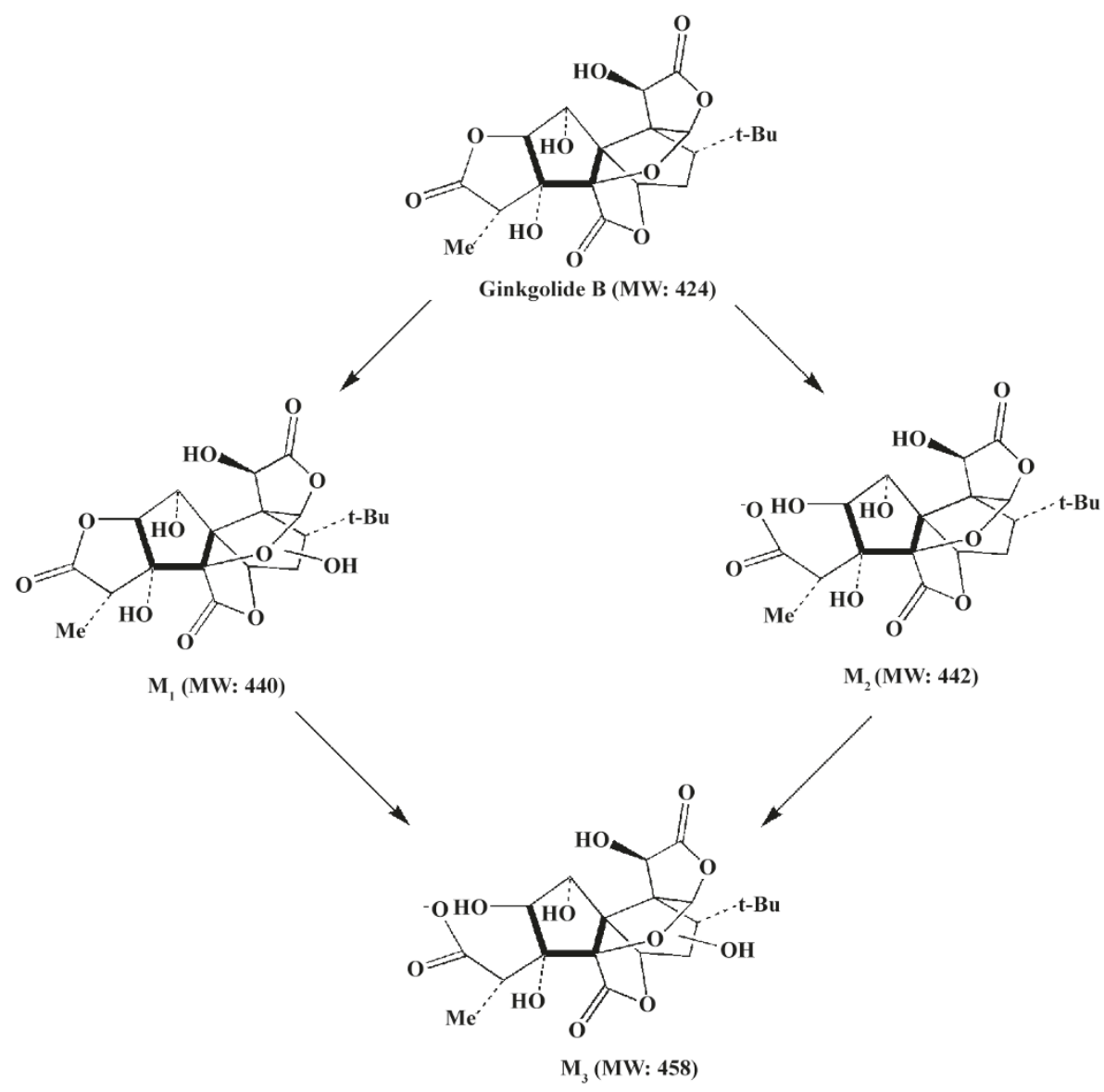

Figure 3. Proposed metabolic pathway of ginkgolide B in rats.

\section{Discussion}

For the first time, LC-IT-TOF-MS with electrospray ionization in negative-ion mode was used for the analysis of ginkgolide B and its metabolites in urine and microsomal incubation. The measurement of the accuracy masses of ions of the parent compounds and metabolites were useful at unambiguously establishing that $\mathrm{M}_{1}(\mathrm{~m} / \mathrm{z}$ 439.124; $\left.\mathrm{C}_{20} \mathrm{H}_{24} \mathrm{O}_{11}\right), \mathrm{M}_{2}\left(\mathrm{~m} / z\right.$ 441.1434; $\left.\mathrm{C}_{20} \mathrm{H}_{26} \mathrm{O}_{11}\right)$, and $\mathrm{M}_{3}$ $\left(\mathrm{m} / z\right.$ 457.1385; $\left.\mathrm{C}_{20} \mathrm{H}_{26} \mathrm{O}_{12}\right)$ had attached a mass equivalent to a $\mathrm{O}, \mathrm{H}_{2} \mathrm{O}$, and $\mathrm{H}_{2} \mathrm{O}_{2}$ moiety relative to the corresponding ginkgolide $\mathrm{B}\left(\mathrm{m} / z\right.$ 423.1334; $\left.\mathrm{C}_{20} \mathrm{H}_{24} \mathrm{O}_{10}\right)$, respectively. Furthermore, abundant main fragment $\mathrm{MS}^{2}$ ions of ginkgolide $\mathrm{B}$ and $\mathrm{M}_{1}$ in the urine and the microsome incubation sample, respectively, by using ion trap mass analyzer, further indicated the loss of 1 and 2 carbon oxide groups of ginkgolide B and its metabolites, which further demonstrated they had a similar mass schizolysis rule and structure core. It identified that $\mathrm{M}_{1}$ is precisely a hydroxyl metabolite of ginkgolide $B$. Comparing $\mathrm{M}_{1}$ in the urine and $\mathrm{M}_{1}$ in the microsome incubation, we found that they had identical retention times and accuracy masses of [M$\mathrm{H}]^{-}$ions, formulas, and $\mathrm{MS}^{2}$ fragments; thus, we confirmed that they were same compound. Therefore, the proposed metabolic pathway of ginkgolide B is metabolized to its hydroxyl metabolite (Figures 4 and 6). Furthermore, the hydroxyl metabolite was not ginkgolide $\mathrm{C}$, based on its retention time being different to that of $\mathrm{M}_{1}$ under the same chromatographic conditions.

In microsomal incubations, various concentrations of ginkgolide B on the rate of the metabolite formation demonstrated that the $K_{\mathrm{m}}$ for $\mathrm{M}_{1}$ was estimated to be approximately $4 \mu \mathrm{mol} / \mathrm{L}$. In chemical inhibition studies, Qui, a CYP2D6 inhibitor, could uncompetitively inhibit the formation of $\mathrm{M}_{1}$, and its $K_{\mathrm{i}}$ value was estimated to be $8 \mu \mathrm{mol} / \mathrm{L}$, while other inhibitors for CYP3A (Ket), CYP2C9 (Sul), CYP1A2 ( $\alpha$-Naph), and CYP2E1 (DDC) had no effect on the formation of $\mathrm{M}_{1}$. The results suggest that CYP2D6 is the major CYP450 isozyme involved in the conversion of 

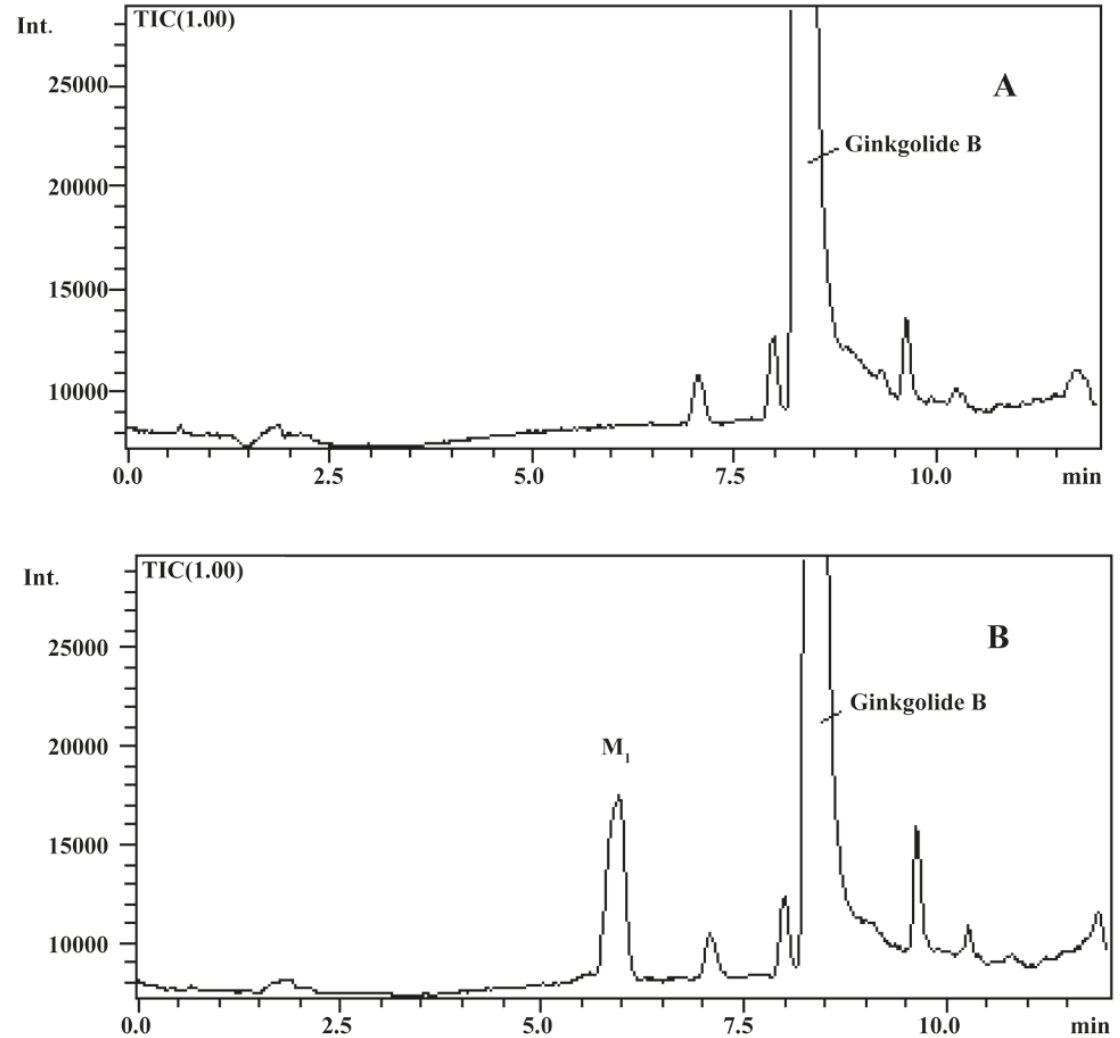

Figure 4. LC/ESI-MS chromatogram of incubation. (A) incubation of ginkgolide B with rat liver microsomes without the NADPH-generating system. (B) incubation of ginkgolide B with rat liver microsomes with the NADPH-generating system.
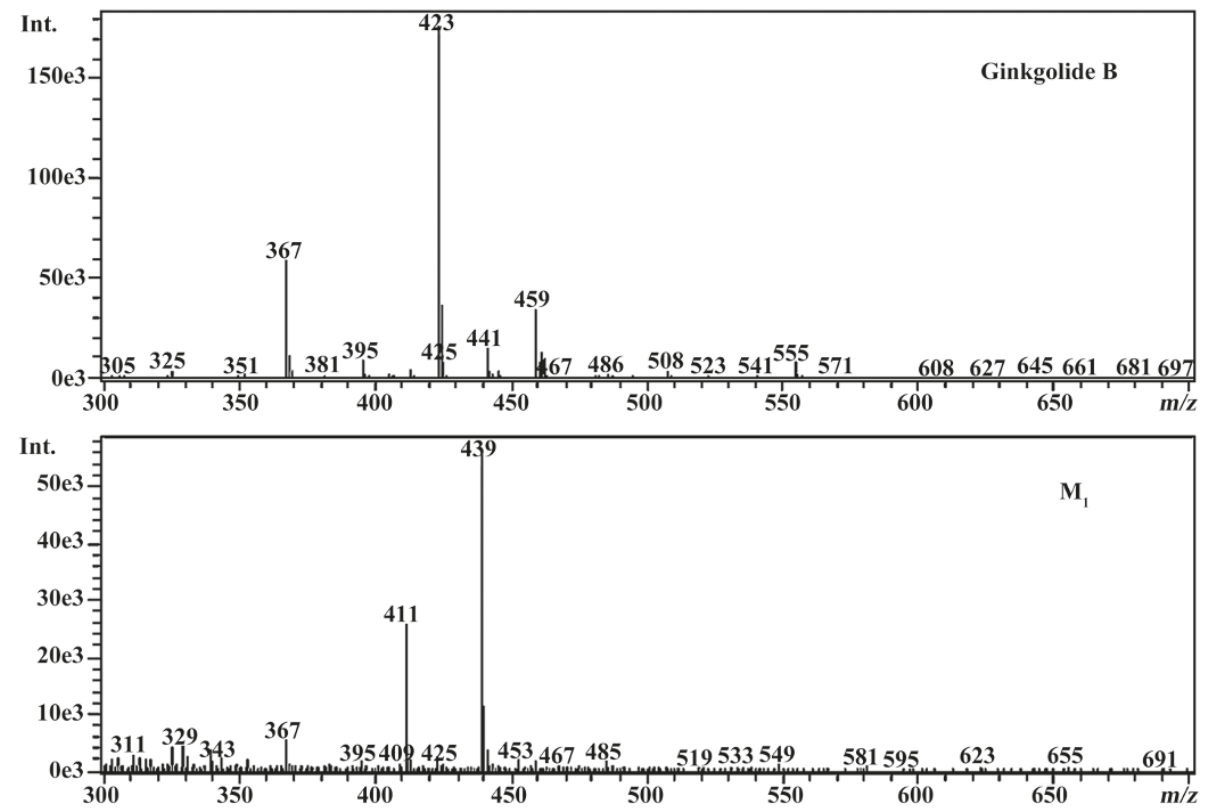

Figure 5. MS spectra of ginkgolide $B$ and its metabolite $M_{1}$ after the incubation of ginkgolide $B$ with rat liver microsomes together with a NADPHgenerating system. 
Table 2. Measured accuracy masses of the $[\mathrm{M}-\mathrm{H}]^{-}$ions of ginkgolide B and its metabolite formed in incubation.

\begin{tabular}{lccccc}
\hline Compound & $\begin{array}{l}\text { Measured mass of } \\
{[\mathrm{M}-\mathrm{H}]^{-} \text {ions/Da }}\end{array}$ & $\begin{array}{l}\text { Predicted mass of } \\
{[\mathrm{M}-\mathrm{H}]^{-} \text {ions/Da }}\end{array}$ & $\begin{array}{l}\text { Suggested elemental } \\
\text { composition }\end{array}$ & $\begin{array}{c}\text { Deviation from the Calculated mass } \\
\mathrm{mDa}\end{array}$ \\
\hline Parent & 423.1334 & 423.1291 & $\mathrm{C}_{20} \mathrm{H}_{24} \mathrm{O}_{10}$ & -4.3 & -10.16 \\
Metabolite $\mathrm{M}_{1}$ & 439.1258 & 439.1240 & $\mathrm{C}_{20} \mathrm{H}_{24} \mathrm{O}_{11}$ & -1.8 & -4.10 \\
\hline
\end{tabular}

Table 3. Measured accuracy mass fragment for the $\mathrm{MS}^{2}$ spectra of ginkgolide B and its metabolites formed in incubation.

\begin{tabular}{|c|c|c|c|c|c|}
\hline Compound & $\begin{array}{l}\text { Measured } \\
\text { fragment mass } / \mathrm{Da}\end{array}$ & $\begin{array}{l}\text { Predicted mass of } \\
{[\mathrm{M}-\mathrm{H}]^{-} \text {ions } / \mathrm{Da}}\end{array}$ & $\begin{array}{l}\text { Suggested elemental } \\
\text { composition }\end{array}$ & $\begin{array}{l}\text { Deviat } \\
\mathrm{mDa}\end{array}$ & $\begin{array}{l}\text { Calculated mass } \\
\text { ppm }\end{array}$ \\
\hline Parent & 367.1423 & 367.1393 & $\mathrm{C}_{18} \mathrm{H}_{24} \mathrm{O}_{8}$ & -3.0 & -8.17 \\
\hline Metabolite $\mathrm{M}_{1}$ & 383.1369 & 383.1342 & $\mathrm{C}_{18} \mathrm{H}_{24} \mathrm{O}_{9}$ & -2.7 & -7.05 \\
\hline
\end{tabular}

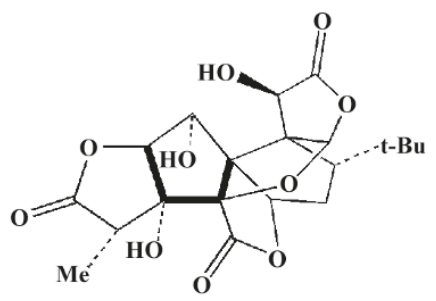

Ginkgolide B (MW: 424)

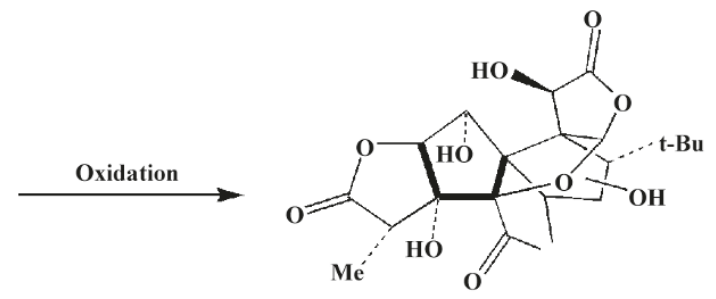

$M_{1}$ (MW: 440)

Figure 6. Proposed metabolic pathway of ginkgolide B in rat liver microsomes.

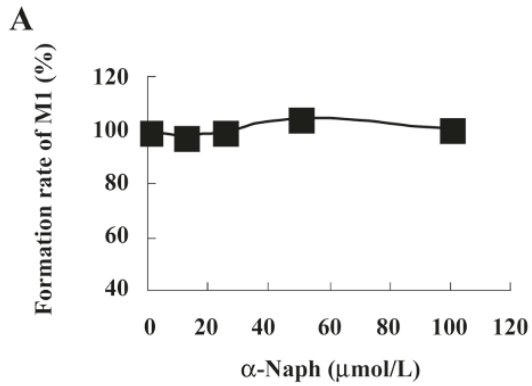

D

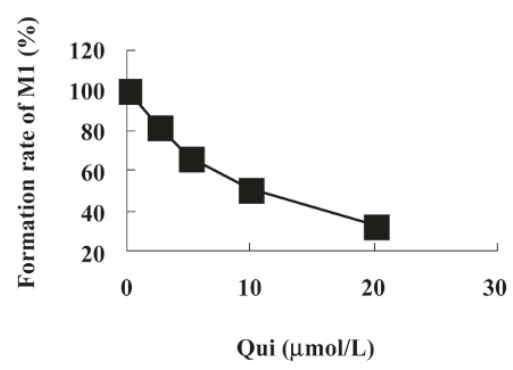

B

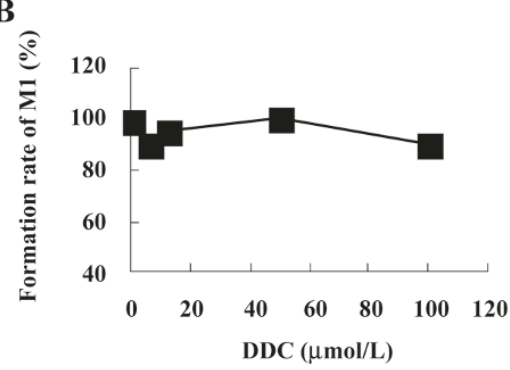

$\mathbf{E}$

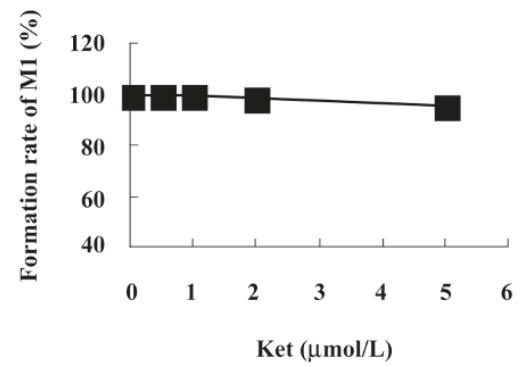

C

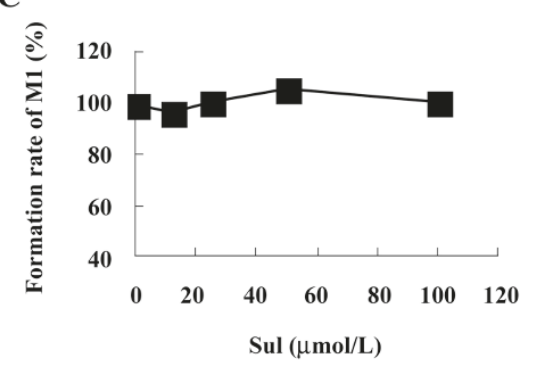

Figure 7. Effects of $\alpha$-Naph (A), DDC (B), Sul (C), Qui (D) and Ket (E) on the formation of metabolite $\mathrm{M}_{1}$ of ginkgolide B (20 $\left.\mu \mathrm{mol} / \mathrm{L}\right)$ in rat liver microsomes, respectively. The vertical axes represented the percent of control values of the inhibitor on the formation of metabolite $\mathrm{M}_{1}$. Each point represents the mean of duplicate determination. 


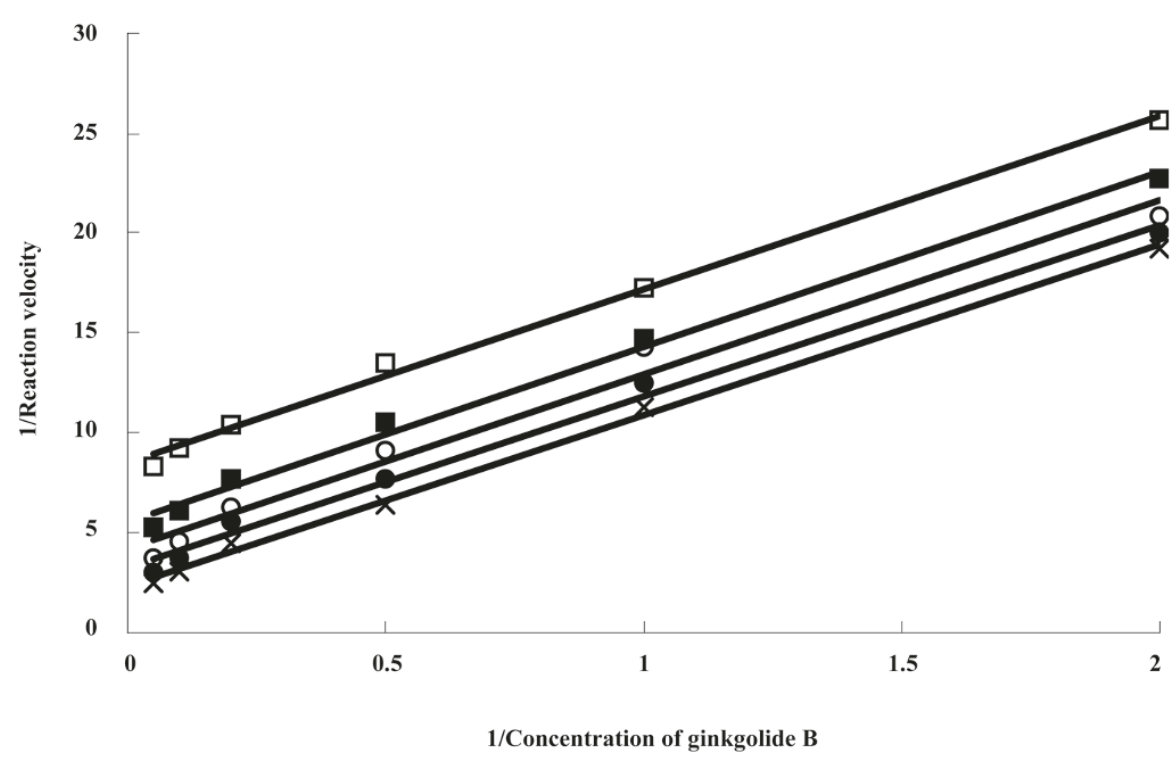

Figure 8. Lineweaver-Burk plot of ginkgolide B $(0.5-20 \mu \mathrm{mol} / \mathrm{L})$ in rat liver microsomes in the absence $(\times)$ and presence of Qui $[2.5 \mu \mathrm{mol} / \mathrm{L}(\bullet), 5 \mu \mathrm{mol} /$ $\left.\mathrm{L}\left({ }^{\circ}\right), 10 \mu \mathrm{mol} / \mathrm{L}(\bullet), 20 \mu \mathrm{mol} / \mathrm{L}(\square)\right]$.

ginkgolide B to hydroxyl metabolite. Pharmacokinetic drug interactions caused by metabolic processes are regarded as one of the most important factors affecting the concentration of drugs. Therefore, the inhibition of the above metabolic pathway can lower the formation rate of the hydroxyl metabolite and increase the concentration of ginkgolide B, suggesting the possibilities of metabolic interactions of ginkgolide B with other therapeutic agents, such as inhibitors and substrates of CYP2D6.

In conclusion, the metabolic pathway ginkgolide B was identified in rats using a high-resolution hybrid LCIT-TOF-MS, which was further confirmed by rat liver microsome incubation in vitro, and the CYP2D6 isozyme was identified as the major CYP450 enzyme responsible for ginkgolide B metabolism in the rat liver microsomes. These results are important for further understanding the disposition of ginkgolide B in rats.

\section{References}

1 Braquet $\mathrm{P}$. Proofs of involvement of PAF-acether in various immune disorders using BN 52021 (ginkgolide B): a powerful PAF-acether antagonist isolated from Ginkgo biloba L. Adv Prostaglandin Thromboxane Leukot Res 1986; 16: 179-98.

2 Prehn JH, Krieglstein J. Platelet-activating factor antagonists reduce excitotoxic damage in cultured neurons from embryonic chick telencephalon and protect the rat hippocampus and neocortex from ischemic injury in vivo. J Neurosci Res 1993; 34: 179-88.

3 Liu XH, Eun BL, Silverstein FS, Barks JD. The platelet-activating factor antagonist BN 52021 attenuates hypoxic-ischemic brain injury in the immature rat. Pediatr Res 1996; 40: 797-803.

4 Koch E. Inhibition of platelet activating factor (PAF)-induced aggregation of human thrombocytes by ginkgolides: considerations on possible bleeding complications after oral intake of Ginkgo biloba extracts. Phytomedicine 2005; 12: 10-6.

5 Beck JC, Goodner CJ, Wilson C, Wilson D, Glidden D, Baskin DG, et al. Effects of ginkgolide B, a platelet-activating factor inhibitor on insulitis in the spontaneously diabetic BB rat. Autoimmunity 1991; 9: 225-35.

6 Oberpichler H, Sauer D, Rossberg C, Mennel HD, Krieglstein J. PAF antagonist ginkgolide $\mathrm{B}$ reduces postischemic neuronal damage in rat brain hippocampus. J Cereb Blood Flow Metab 1990; 10: 133-5.

7 Bate C, Salmona M, Williams A. Ginkgolide B inhibits the neurotoxicity of prions or amyloid- $\beta_{1-42}$. J Neuroinflammation 2004; 1: 4-11.

8 Chen WD, Liang Y, Xie L, Lu T, Liu XD, Wang GJ. Pharmacokintics of the ginkgo B following intravenous administration of ginkgo B emulsion in rats. Biol Pharm Bull 2007; 30: 1-5.

9 Liu XQ, Zhao Y, Li D, Qian ZY, Wang GJ. Metabolism and metabolic inhibition of clinipine in human liver microsomes. Acta Pharmacol Sin 2003; 24: 263-8.

10 Lowry OH, Rosebrough NJ, Farr AL, Randall RJ. Protein measurement with the folin-phenol reagent. J Biol Chem 1951; 193: 265-75.

11 Liu YT, Hao K, Liu XQ, Wang GJ. Metabolism and metabolic inhibition of gambogic acid in rat liver microsomes. Acta Pharmacol Sin 2006; 27: 1253-8.

12 Van Beek TA. Ginkgolides and bilobalide: Their physical, chromatographic and spectroscopic properties. Bioorg Med Chem 2005; 13: 5001-12.

13 Suehiro M, Simpson NR, Underwood MD, Castrillon J, Nakanishi K, Van Heertum R. In vivo biodistribution of ginkgolide B, a constituent of Ginkgo biloba, visualized by MicroPET. Planta Med 2005; 71: $622-7$. 